\title{
ТЕРПЕНОИДЫ В ДИЗАЙНЕ \\ ПОТЕНЦИАЛЬНЫХ ГИПОГЛИКЕМИЧЕСКИХ АГЕНТОВ МУЛЬТИТАРГЕТНОГО ДЕЙСТВИЯ
}

\author{
С.О. Куранов, О.А. Лузина, Н.Ф. Салахутдинов \\ ЛФАВ, НИОХ СО РАН, \\ 630090, Россия, Новосибирск, проспект Академика Лаврентьева, 9. \\ E-mail:s.o.kuranov@chemomsu.ru
}

DOI: 10.19163/MedChemRussia2021-2021-292

Сахарный диабет второго типа является серьезной проблемой для современного здравоохранения. Несмотря на большое количество существующих вариантов терапии, у подавляющего числа пациентов не удаётся добиться удовлетворительной компенсации симптомов, поэтому поиск новых гипогликемических агентов является актуальной задачей.

Ранее нами было синтезировано соединение 1, совмещающее в своей структуре борнильный остов с фрагментом фенилпропановой кислоты. Было показано, что соединение 1 проявляет гипогликемическую активность в тестах in vivo, что может быть связано, согласно in silico расчетам, с его мультитаргетным действием [1, 2].<smiles>[R]NCc1ccc(COc2ccc(CCC(=O)O)cc2)cc1</smiles>

$R=$
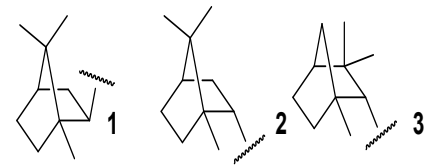

Для развития подходов к синтезу структурных аналогов соединения 1 нами предложена новая методика, заключающаяся в последовательных реакциях функционально замещенного терпеноида, бромометилбензальдегида и метил (4 гидроксифенил) пропаноата. С использованием данного подхода получены соединения 1-3. Изучение их биологической активности позволит провести анализ закономерностей «структура - активность».

Выполнено при поддержке гранта РНФ 20-13-00029.

\section{Литература}

[1] S. Kuranov, et al., Bioorganic Chemistry. 2020, 99, 103830.

[2] S. Kuranov, et al., Pharmaceuticals. 2020, 13, 404. 